\title{
Práticas Efetivas em Educação Matemática no contexto de um banco comunitário
}

\author{
Effective practices in mathematical education in the context \\ of a community bank
}

\author{
Renata Cristina Geromel Meneghetti* \\ Rita de Cássia Zacheo Barrofaldi**
}

\begin{abstract}
Resumo
A pesquisa que embasa este artigo refere-se a um projeto que focaliza a Educação Matemática no contexto da Economia Solidária. Neste artigo enfocamos o caso de um Banco Comunitário (BC). O trabalho teve como propósito ensinar e desenvolver atividades matemáticas de forma contextualizada, visando atender a demandas específicas na implementação de Empreendimentos em Economia solidária. Com isso, visou-se, também, criar subsídios para colaborar com práticas educativas em matemática no contexto da Economia Solidária. A pesquisa seguiu uma abordagem qualitativa de investigação (estudo de caso); os dados foram levantados por meio de observação participante e entrevistas semiestruturadas. Como resultado, observou-se que a Matemática é importante principalmente quanto à gestão financeira e logística do $\mathrm{BC}$; as intervenções pedagógicas em matemática, realizadas nesse contexto, auxiliaram o grupo quanto à organização e à compreensão das atividades do BC, além de contribuírem com a autogestão desse Empreendimento em Economia Solidária (EES).
\end{abstract}

Palavras-chave: Educação Matemática. Educação de Jovens e Adultos. Etnomatemática. Economia Solidária. Banco Comunitário. Autogestão.

\begin{abstract}
This paper is part of a project that focuses on the Mathematical Education in the context of Solidarity Economy and takes a Community Bank (CB) as a case study. It aims at the teaching and development of Mathematical activities in a contextualized way, so that the specific demands for the implementation of Enterprises in Solidarity Economy can be met, as well as the creation of some subsidies for the development of such activities. The research followed a qualitative approach (case study) and the data were collected through participant observations and semi-structured interviews. The results show Mathematics is very important to the financial management and logistics of the $\mathrm{CB}$ and the educational interventions made assisted the group in the organization to understand the activities of the $\mathrm{CB}$ and also contributed to the self-management of this Undertaking Solidarity Economy (EES).
\end{abstract}

Keywords: Mathematics Education. Youth and Adult Education. Ethnomathematics. Solidarity Economy. Self management.

\footnotetext{
* Doutora em Educação Matemática pela Universidade Estadual Paulista (UNESP). Docente do Instituto de Ciências Matemáticas de Computação da Universidade de São Paulo (ICMC-USP), São Carlos, São Paulo, Brasil. Endereço para correspondência: Avenida trabalhador são-carlense, n.400, centro (USP/ICMC/Departamento de Matemática), CEP:13566-590, São Carlos/SP, Brasil. E-mail: rcgm@icmc.usp.br

Licenciada em Matemática pela Universidade de São Paulo (USP).Endereço para correspondência:Av Dr. Tancredo de Almeida Neves, 457, Apto. 202, Pq. Santa Mônica, 13561-260, São Carlos, SP, Brasil. Email: ritazacheo@hotmail.com
} 


\section{Introdução}

Este trabalho é parte de um projeto de pesquisa que foca a Educação Matemática no contexto da Economia Solidária, que se dá em parceria (firmada pela primeira autora) com o NuMI-EcoSol ${ }^{1}$ e que visa compreender e atender a demandas específicas inerentes à implementação de empreendimentos em economia solidária (EES), em especial no que diz respeito aos conhecimentos matemáticos subjacentes às atividades desses EES. Neste artigo focalizamos o caso de um Banco Comunitário (BC), que é caracterizado como um EES e foi criado como condição para o desenvolvimento socioeconômico de bairros carentes de uma cidade localizada no interior do Estado de São Paulo.

A Economia Solidária pode ser entendida, sinteticamente, como o "conjunto de atividades econômicas - de produção, distribuição, consumo, poupança e crédito organizadas e realizadas solidariamente por trabalhadores e trabalhadoras sob a forma coletiva e autogestionária" (BRASIL, 2006a, p. 11). Desta, podem fazer parte diversos tipos de empreendimentos, tais como cooperativas, associações, clubes de troca, empresas recuperadas autogeridas, organizações de finanças solidárias, grupos informais etc. Tais empreendimentos são denominados de Empreendimentos em Economia Solidária (EES) e são caracterizados por algum tipo de atividade econômica, pela cooperação, solidariedade e autogestão.

$\mathrm{Na}$ implementação desses EES há uma vertente educacional denominada Educação em Economia Solidária, a mesma deve levar em conta “[...] a solidariedade em sua dimensão ontológica (condição humana, constitutiva da vida social), bem como as diferentes concepções e práticas de solidariedade que se manifestam em diversos espaços/tempos históricos e, inclusive, convivem num mesmo espaço físico/subjetivo.” (BRASIL, 2006b, p. $15)$.

Nesse contexto, identificamos uma demanda específica da Educação Matemática, que se refere aos conhecimentos matemáticos necessários à implementação de tais empreendimentos, pois seus integrantes precisam se apropriar desses conhecimentos que são inerentes às atividades que realizam no cotidiano de trabalho desses empreendimentos.

A pergunta norteadora desta investigação é: Como a matemática pode ser ensinada e utilizada, visando à aquisição e à compreensão de conhecimentos matemáticos inerentes às atividades do $\mathrm{BC}$ e, ao mesmo tempo, o fortalecimento dos princípios da Economia Solidária?

\footnotetext{
1 NuMI-EcoSol - Núcleo Multidisciplinar e Integrado de Estudos, Formação e Intervenção em Economia Solidária - com sede na UFSCar, mas é aberto à participação de pesquisadores de diversas universidades. Esse núcleo é responsável pelos processos de incubação de empreendimentos econômicos solidários, em várias atividades econômicas e diversas localidades.
} 
Assim, no que se refere à Educação Matemática, este trabalho teve como propósito ensinar matemática e desenvolver atividades relacionadas a essa ciência, de forma contextualizada, visando atender a demandas específicas do Banco Comunitário, auxiliando seus membros na aquisição e compreensão de conhecimentos matemáticos inerentes ao cotidiano desse EES. Com isso, busca-se, também, criar subsídios para colaborar com práticas educativas em matemática no contexto da Economia Solidária. No que se refere à Economia Solidária, buscou-se colaborar com o fortalecimento dos princípios da Economia Solidária, em especial com a autogestão do $\mathrm{BC}$, visando maior autonomia na realização das atividades do cotidiano de trabalho desse EES.

\section{Referencial teórico}

Em nossa trajetória, devido à natureza do trabalho realizado, alguns pressupostos teóricos da Economia Solidária foram considerados; no contexto educacional nos pautamos, principalmente, nos pressupostos teóricos da Educação de Jovens e Adultos e da Etnomatemática.

\subsection{Considerações teóricas sobre a Economia Solidária}

A Economia Solidária (ES) é um modo de organização das atividades econômicas (produção, comercialização e consumo) pautada na autogestão e na cooperação, cuja finalidade é a valorização dos seres humanos ao invés da valorização do capital. O trabalho é compreendido como uma atividade emancipadora, um meio de suprir as necessidades e, ao mesmo tempo, de libertação humana dentro de um processo de democratização econômica, criando uma alternativa ao modelo alienante do capitalismo.

Quando se pensa em Economia Solidária tem-se em mente um modo de produção com alicerce na igualdade, por meio da cooperação entre os participantes. Esse tipo de economia se caracteriza como uma alternativa para a superação das desigualdades criadas pelo capitalismo. Por isso, ações em Economia Solidária geralmente acontecem por parte daqueles que foram desprivilegiados pela sociedade do capital. No Brasil, ao longo dos últimos quinze anos, a Economia Solidária vem ganhando amplitude enquanto movimento social.

De acordo com Singer (1998), as ideias cooperativistas se desenvolveram concomitantemente ao avanço da industrialização, como reação ao empobrecimento dos artesãos, provocado pela difusão das máquinas e da organização fabril da produção. Ao longo 
do tempo, o movimento cooperativista passou por avanços e recuos, sendo que a emergência de cooperativas e demais alternativas coletivas de organização do trabalho se acentuou em momentos de crise econômica, com objetivo principal de atenuar situações de desemprego e buscar por melhor qualidade de vida.

Segundo Brasil (2006a), a Economia Solidária necessita apresentar quatro características para ser reconhecida como tal: cooperação, autogestão, viabilidade econômica e solidariedade.

A cooperação é compreendida como a existência de interesses e objetivos comuns; a união de esforços e capacidades; e a responsabilidade solidária para a superação das dificuldades. A autogestão refere-se ao exercício de práticas participativas no proceso de trabalho e definições de estratégias no cotidiano do EES; são práticas que se caracterizam pela natureza democrática, propiciando a autonomia do grupo em relação às atividades realizadas. A viabilidade econômica se dá por meio da união de esforços, recursos e conhecimentos, a fim de tornar viáveis iniciativas coletivas do grupo no que diz respeito à produção, prestação de serviços, beneficiamento, crédito, comercialização e consumo. A solidariedade diz respeito à preocupação contínua com a distribuição justa dos resultados, bem como a melhoria das condições de vida dos envolvidos; beneficiando não somente os membros dos empreendimentos, mas, também, a comunidade da qual eles fazem parte (BRASIL, 2006a).

Singer (2002) salienta que na Economia Solidária a prática da autogestão é a característica principal, pois se trata de uma administração que ocorre de forma democrática. A autogestão tem como mérito não só a eficiência econômica, mas, também, o desenvolvimento humano que proporciona: "Participar das discussões e decisões do coletivo, ao qual se está associado, educa e conscientiza, tornando a pessoa mais realizada, autoconfiante e segura" (SINGER, 2002, p. 21).

Entretanto, ainda segundo esse autor, essa prática exige um esforço adicional dos trabalhadores, visto que além de cumprir com as tarefas diárias junto ao empreendimento, cada um tem de se preocupar com os problemas originados dele; isso pode implicar numa reeducação coletiva dos trabalhadores, a fim de que eles se ajudem mutuamente e tomem as decisões coletivamente. Assim, os trabalhadores associados à Economia Solidária estão inseridos em um processo de democratização econômica, no qual a educação tem um papel fundamental.

\subsection{Considerações teóricas sobre a Educação no contexto da Economia Solidária e a} Educação de Jovens e Adultos 
A Educação no contexto da Economia Solidária está associada à Educação de Jovens e Adultos, pois os membros dos EES são, em geral, pessoas adultas que possuem uma experiência de vida e trazem consigo um contexto sócioetnocultural.

Para Corôa (2006) a especificidade sociocultural está, muitas vezes, voltada a uma classe social menos favorecida:

Na EJA, seus alunos, tanto jovens como adultos, são em maioria, trabalhadores que tiveram que parar de estudar ou nunca estudaram para poder trabalhar e sustentar suas famílias. São geralmente excluídos da sociedade por sua condição de não escolarizado, o que provoca entre eles baixa autoestima e o sentimento de inferioridade em relação àqueles escolarizados ou alfabetizados e até mesmo perante sua família (CORÔA, 2006, p. 33).

Dessa forma, as diretrizes curriculares para EJA destacam a importância de se trabalhar com situações contextualizadas (BRASIL, 2002). Segundo esse documento, isso pode colaborar para uma aprendizagem mais significativa, já que tais situações favorecem a compreensão e contribuem para a construção de conhecimentos matemáticos que, por sua vez, são ferramentas importantes para a compreensão da realidade. Nesse contexto, Freire (2011) também destaca a importância de se trabalhar um conteúdo de ensino através de situações que refletem o cotidiano dessas pessoas:

O conceito de Educação de Adultos vai se movendo na direção da Educação Popular na medida em que a realidade começa a fazer algumas exigências à sensibilidade e à competência científica dos educadores. [...] Os próprios conteúdos a serem ensinados não podem ser totalmente estranhos àquela cotidianidade. O que acontece, no meio popular, nada pode escapar à curiosidade arguta dos educadores envolvidos na prática da Educação Popular (FREIRE, 2011, p. 21-22).

Pode-se afirmar, então, que para Freire (2011) as práticas educativas na Educação de Jovens e Adultos rompem com o horizonte discriminatório da educação, dando origem a concepção de Educação Popular, que está fundamentada na compreensão de uma educação, realizada por meio de processos contínuos e permanentes de formação, que tem a intenção de transformar a realidade dos sujeitos através da própria educação.

Paula (2009) destaca que este tipo de educação tem origem no Brasil na década de 20 com o manifesto dos pioneiros da Escola Nova no qual se defendia a educação popular para todos. Entretanto salienta essa autora que foi a partir da década de 60, com o processo de urbanização e industrialização, que o Brasil passou a se preocupar mais com o alto índice de analfabetismo de jovens e adultos das classes populares, em virtude da necessidade da mão de obra qualificada para o trabalho.

Segundo essa autora, 
Um dos objetivos principais, nos primórdios da Educação Popular era de buscar promover a participação dos sujeitos na construção de um projeto político de sociedade através de soluções construídas coletivamente, nas quais se pretendia superar as desigualdades sociais, principalmente no que se refere às desigualdades existentes no campo educacional. (PAULA, 2009, p. 6136).

Assim, tal como salienta Viero (2008), a Educação Popular nasce no interior dos movimentos dos trabalhadores e dos movimentos populares e tem relação com os seus projetos de sociedade. Em tal contexto, consideram-se os saberes que os trabalhadores trazem das suas práticas cotidianas. Este tipo de Educação Popular valoriza os saberes prévios de um dado grupo de indivíduos, os quais emergem de suas realidades culturais e culminam na construção de novos saberes. Está inteiramente ligada a um olhar crítico, que propicia o desenvolvimento da comunidade na qual o indivíduo está inserido, pois estimula o diálogo e participação comunitária, possibilitando uma melhor interpretação de realidade social, política e econômica, ou seja, do contexto sociocultural do indivíduo.

A educação de jovens e adultos é um campo de sentido amplo cujas práticas e reflexões vão além dos limites da escolarização em sentido estrito, ou seja, da escola formal; é um processo contínuo na busca da construção do conhecimento necessário para lidar com as situações cotidianas. Assim,

\begin{abstract}
Quando falamos em educação de jovens e adultos, podemos afirmar que a mesma está inserida dentro de um contexto de educação permanente, onde os diferentes espaços e pessoas se relacionam, transformando-se por meio de um processo contínuo, procurando chegar ao conhecimento verdadeiro de tudo o que se é capaz. Para entender melhor a essência da educação de jovens e adultos, além de partir de uma realidade concreta onde os fatos acontecem no cotidiano de suas vidas, devemos desenvolver nos alunos de forma generalizada a visão de um mundo complexo e agitado, possibilitando condições que lhes permitam navegar por este mesmo mundo (OLIVEIRA; BOLIS, 2003 apud PEREIRA, 2006, p. 13).
\end{abstract}

Vale ressaltar que, neste trabalho, o foco está no contexto da educação não formal, pois as intervenções pedagógicas ocorreram no próprio ambiente de trabalho do BC e não no ambiente escolar.

Para entendermos melhor os pressupostos da educação não formal, é necessário diferenciá-la da educação formal. A educação formal é definida como aquela que tem reconhecimento oficial, oferecida nas escolas em cursos com níveis, graus, programas, currículos e diplomas e regulada por diretrizes governamentais (municipais, estaduais e federais). A educação não formal, por sua vez, não ocorre em lugares preestabelecidos (escolas), não precisa obedecer cargas-horárias ou currículos pré-determinados (GASPAR, 2002).

Ainda segundo esse autor, na Educação não formal: 
Os conhecimentos são partilhados em meio a uma interação sociocultural que tem, como única condição necessária e suficiente, existir quem saiba e quem queira ou precise saber. Nela, ensino e aprendizagem ocorrem espontaneamente, sem que, na maioria das vezes, os próprios participantes do processo tenham consciência (GASPAR, 2002, p. 173).

Segundo Paula (2009), as ações referentes à educação não formal no Brasil tiveram origem a partir dos anos 90, em decorrência de mudanças na economia, na sociedade e no mundo do trabalho. Este tipo de educação surgiu como uma possibilidade entre o Estado e as populações na busca pela construção de propostas curriculares alternativas para as crianças e adolescentes excluídos das escolas formais.

Segundo Gohn (2006), educação não formal ocorre em espaço não escolares, o objetivo principal deste tipo de educação é a capacitação de cidadãos (formar os individuos para a vida e suas adversidades; capacitá-los para o trabalho); a principal característica da educação não formal é o fato dela não ser organizada por série/idade/conteúdo, atuando sobre aspectos subjetivos, trabalhando e formando a cultura política de um grupo e visando a construção de sua identidade coletiva. Em termos da aprendizagem trata-se de um processo multidimensional, que foca:

[...] aprendizagem política dos direitos dos indivíduos enquanto cidadãos; a capacitação dos indivíduos para o trabalho, por meio da aprendizagem de habilidades e/ ou desenvolvimento de potencialidades; a aprendizagem e exercício de práticas que capacitam os indivíduos a se organizarem com objetivos comunitários, voltadas para a solução de problemas coletivos cotidianos; a aprendizagem de conteúdos que possibilitem aos indivíduos fazerem uma leitura do mundo do ponto de vista de compreensão do que se passa ao seu redor; a educação desenvolvida na mídia e pela mídia, em especial a eletrônica etc. (GOHN, 2006, p. 28).

Portanto, nossas práticas efetivas de educação matemática no contexto do BC referemse a educação de jovens e adultos e ocorreram nos moldes da educação-não formal.

\subsection{Considerações teóricas sobre a Etnomatemática}

No âmbito da Educação Matemática, este trabalho vai ao encontro das concepções de educação do programa Etnomatemática, visto que, nesse programa, a educação é entendida como uma estratégia de estímulo ao desenvolvimento (individual e coletivo) com a finalidade de se manter como tal e de avançar na satisfação das necessidades de sobrevivência e de transcendência (D'AMBROSIO, 2001). De acordo com esse autor, a Etnomatemática é entendida como uma técnica de entender a realidade, no interior de um contexto cultural próprio. Assim, a Etnomatemática, ao reconhecer a dinâmica inter e intracultural da sociedade, encontra ferramentas que podem dar sentido às ações humanas do nosso dia a dia. 
Para D’Ambrosio (1996) a Etnomatemática permite entender o processo cognitivo numa relação dialética entre códigos e símbolos, a partir da qual é possível propor práticas educacionais. Assim, a aquisição do conhecimento ocorre por meio de uma relação dialética entre o saber e o fazer, impulsionada pela consciência. Pode-se, então, dizer que a ação do saber e do fazer, que gera o conhecimento, está intimamente ligada à cultura ${ }^{2}$ do indivíduo. Em relação à educação, esse autor defende que é necessário reconhecer que cada indivíduo é um todo integral e integrado e que suas práticas (tanto cognitivas quanto organizativas) não são desvinculadas do contexto histórico. Com isso, ele defende a universalização da educação, a fim de atingir toda a população, buscando preservar a diversidade e eliminar as desigualdades.

Nesse sentido, como já destacado em Meneghetti (2013), o Programa Etnomatemática possibilita olhar para os EES e buscar, em primeiro lugar, identificar o saber matemático utilizado pelos seus integrantes em seus afazeres no cotidiano de trabalho e, a partir dessa contextualização, por meio de um trabalho educacional em conjunto, procura-se transcender esse fazer rumo à autogestão do EES, que é um dos principais propósitos a se alcançar na Economia Solidária.

Nessa direção, entende-se que o conhecimento matemático pode nos ajudar na resolução de problemas da vida real, tal como destacado por Mafra (2002, p. 3):

As ideias relacionadas ao conhecimento matemático estão vinculadas à realidade
existencial e atendem as necessidades básicas no processo de modelar e procura
explicações para as atividades diversas no momento presente, pois poderíamos supor
a necessidade de obtermos respostas mais complexas à medida que caminhamos
para a resolução de problemas reais evidentemente mais complexos. Nesse sentido
os problemas (consequentemente, as ideias matemáticas estabelecidas na resolução
dos mesmos) estariam ligados aos modos de vida dessas populações e refletiriam
elementos geradores nas mesmas, ou seja, estaríamos diante de elementos
determinados pela formação cultural dos diferentes povos.

Diante do apresentado, nesta pesquisa o programa Etnomatemática foi empregado como suporte teórico-metodológico em dois momentos: no levantamento inicial, no qual se buscou conhecer o cotidiano do $\mathrm{BC}$, e também para nortear as intervernções pedagógicas realizadas.

De acordo com Knijnik (2009) a Etnomatemática tem por objetivo dar visibilidade a outras culturas, buscando inclusão social. Outra maneira que a autora classifica esse tipo de saber é como saber particular, regional ou local. (KNIJNIK, 2009). Para essa autora não se deve entender que há rejeição/abandono da Matemática acadêmica, nem supervalorização das

\footnotetext{
${ }^{2}$ A cultura é entendida como essência do conhecimento, dos saberes e fazeres e do comportamento resultante, comum em um grupo, comunidade ou povo; segundo o autor é a cultura que permite a vida em sociedade, cada indivíduo organiza seu processo intelectual ao longo de sua história de vida (D’AMBROSIO, 2005).
} 
raízes de alguns indivíduos em relação a outros; o que se tenta é que cada indivíduo reforce suas próprias raízes.

Ainda de acordo com a autora, para desenvolver uma educação matemática para todos, não basta apenas contextualizar o grupo social do individuo. Temos, também, que entender a função de cada pessoa que faz parte desse grupo; vale destacar que essa foi uma tarefa que procuramos efetuar durante nosso contato e atuação junto ao BC. Moreira (2009) destaca que as necessidades individuais são diferentes e, por conta disso, a resposta, por parte da escola, deve ser individualizada. Segundo essa autora a Educação ideal é aquela que contribui para a inclusão e interação entre as várias dimensões da vida social.

Rosa e Orey (2006), ao discutirem sobre possibilidades de ações pedagógicas no contexto da Etnomatemática, salientam tanto a importância de os indivíduos desenvolverem suas próprias práticas matemáticas como, também, que tenham uma compreensão da matemática acadêmica. Esses autores ainda destacam que isso pode ser obtido através de ações pedagógicas que estabeleçam uma ligação da matemática presente na comunidade com a matemática acadêmica (escolar).

Nesse sentido, entendemos que foi necessário primeiro compreender a Matemática utilizada no BC e a forma e como ela era utilizada. Somente a partir disso é que se elaborou as atividades trabalhadas nas intervenções pedagógicas junto ao BC Tais atividades priorizaram o cotidiano do grupo, buscando fazer uma ligação entre a matemática presente nesse cotidiano com a matemática escolar.

\section{Metodologia empregada}

O trabalho seguiu uma abordagem qualitativa de investigação, estudo de caso (LÜDKE; ANDRÉ, 1986), porém com elementos da pesquisa-ação (THIOLLENT, 2011), visto que membros dos empreendimentos e pesquisadores buscaram atuar de modo cooperativo em uma realidade social específica, com a finalidade de promover mudanças no contexto social, trazendo benefícios e crescimento a todos os envolvidos.

A pesquisa foi efetuada seguindo as etapas: num primeiro momento, buscou-se conhecer, por meio de observação participante e de entrevistas semiestruturadas, o contexto social do BC, visando compreender o dia a dia desse empreendimento; buscando identificar os saberes matemáticos necessários em sua cadeia produtiva e as dificuldades dos membros do $\mathrm{BC}$ com esse tipo de saberes. A partir dos elementos obtidos nessa primeira fase, verificouse quais possibilidades de estratégias de ensino e aprendizagem e realização de intervenções 
pedagógicas em matemática, visando sanar as dificuldades dos membros desse EES, poderiam ser utilizadas.

O levantamento inicial realizado mostrou que praticamente todas as atividades efetuadas no BC giravam em torno de se manusear uma planilha de análise e de controle de crédito produtivo, utilizada para a análise e concessão de empréstimos. Tal planilha refere-se a dois tipos de empréstimos: crédito de consumo ${ }^{3}$ e crédito produtivo ${ }^{4}$. Ainda nessa primeira fase, identificou-se que a maior dificuldade que as integrantes enfrentavam consistia, justamente, no uso dessa planilha, mais especificamente, em relação aos conceitos matemáticos necessários para seu preenchimento e análise, que envolvem operações básicas com números decimais, cálculo de médias, porcentagens, regra de três e conversões de medidas. A referida planilha possui campos onde é possível preencher os dados de um EES, tais como gastos e ganhos familiares, gastos com o empreendimento, compra de matéria prima, valor de venda das mercadorias, média de venda mensal, lucros etc.

A partir desse levantamento, foi elaborada uma proposta de atividades, focando situações-problemas no contexto da utilização dessa planilha, simulando análise de empreendimentos solicitando empréstimo. As atividades foram realizadas através de dez oficinas pedagógicas de educação matemática com duração de uma hora cada, que ocorreram em dias distintos e de acordo com a possibilidade dos integrantes de BC.

\section{Sobre o Banco Comunitário}

O Banco Comunitário, EES focado nesse trabalho, abriu suas portas ao público, pela primeira vez, no dia 25 de junho de 2012, com o objetivo de oferecer à população de um bairro empobrecido, serviços financeiros comunitários de baixo custo e de forma participativa, visando estimular o desenvolvimento da economia local. Foi a primeira iniciativa de Economia Solidária dessa natureza no interior do estado de São Paulo (TAFURI, 2014).

\footnotetext{
${ }^{3} \mathrm{O}$ crédito de consumo é uma linha de crédito que se destina aos moradores do bairro que necessitam de dinheiro para a compra de artigos de primeira necessidade, como por exemplo, medicamentos, fraldas etc; esse tipo de crédito é concedido na moeda social VIDA (V\$), sendo que o limite para concessão de crédito de consumo é de V\$ 100,00 (cem vidas) que pode ser dividido no máximo em 03 (três) parcelas sem juros.

${ }^{4} \mathrm{O}$ crédito produtivo é uma linha de crédito destinada aos moradores que pretendem abrir ou possuem um empreendimento no bairro, cujas características do mesmo devem ser as de um empreendimento da Economia Solidária (EES), podendo ser Familiar ou Coletivo, ou da Economia Popular.
} 
$\mathrm{Na}$ fase de nossa atuação junto ao BC, esse EES era composto por três pessoas, agentes de crédito, que serão aqui designadas por: $A, B$ e $C^{5}$. As três integrantes do $\mathrm{BC}$ possuíam grau de escolaridade diferente; enquanto a $A$ e $B$ tinham concluído o ensino médio há bastante tempo, a $\mathrm{C}$ precisou interromper os estudos quando cursava a segunda série do ensino médio.

Ainda de acordo com Tafuri (2014), de maneira específica, as principais atividades realizadas pelos agentes de crédito decorrem do trabalho relativo ao processo de divulgação, análise e concessão dos créditos produtivos e de consumo, tais como: informação aos moradores do bairro sobre as atividades do banco e os serviços financeiros que ele oferece; mobilização a comunidade para apoio e divulgação das ações do banco; visitas aos solicitantes de empréstimo, preenchimento das fichas de análise de crédito e busca de informações (referências) sobre eles; análise das solicitações de crédito; elaboração de relatórios sobre as visitas realizadas junto aos empreendimentos que solicitam crédito; apresentação desses relatórios ao Comitê de Análise de Crédito (CAC); acompanhamento e controle da carteira de créditos.

\subsection{Sobre o levantamento inicial e as atividades elaboradas}

No desenvolvimento das atividades desenvolvidas junto ao $\mathrm{BC}$, a ênfase foi dada à planilha de análise de controle de crédito produtivo, pois de acordo com o levantamento inicial realizado, o manuseio dessa planilha estava causando bastante dificuldade às integrantes do banco. Essa planilha estava apresentada em um documento elaborado em Word, possuía dezesseis páginas constituídas de tabelas que eram preenchidas pelos integrantes do Banco Comunitário com informações acerca do EES que solicitou o crédito. As tabelas continham espaços que deveriam ser preenchidos, após efetuar alguns cálculos, como por exemplo, conversões para quantidade de matérias-primas, quantidade, custo de cada unidade do produto, gasto total. Ainda se calculava, em relação ao EES solicitante de crédito, margem de contribuição, total das sobras e das vendas. O resultado do negócio era calculado considerando as receitas apuradas por duas fontes de informação: média mensal de vendas e compra mensal.

Para as intervenções pedagógicas foram utilizadas situações-problemas que simulavam o contexto de um EES na solicitação de um empréstimo. Assim, os conteúdos foram

\footnotetext{
${ }^{5}$ Utilizamos as letras $A, B$, e $C$ a fim de preservar a identidade dos sujeitos do trabalho.
} 
trabalhados de forma contextualizada e envolveram os conceitos de: porcentagem, razão e proporção, regra de três e operações básicas com números racionais, os quais foram percebidos pelos pesquisadores como inerentes à realização das atividades diárias envolvendo matemática do EES.

O Quadro 1 traz um exemplo de uma das atividades trabalhadas com o grupo, que foi retirada do plano proposto para as intervenções pedagógicas:

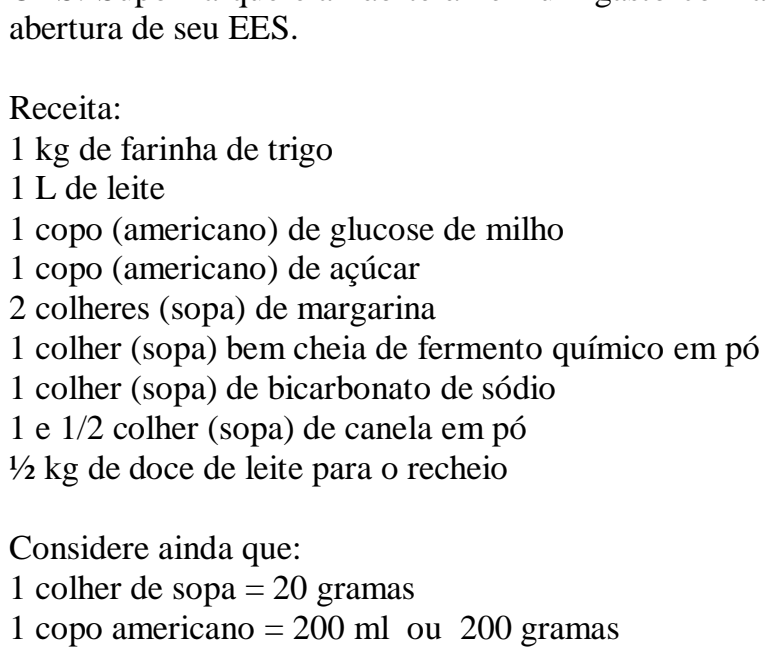

Observe a tabela abaixo, que pode ser usada como apoio para o cálculo do custo da unidade de pão de mel e complete-a de acordo com as informações obtidas anteriormente, de modo que possamos encontrar o custo da unidade de pão de mel.

\begin{tabular}{|c|c|c|c|c|}
\hline MATÉRIA-PRIMA & QUANTIDADE & CUSTO & $\begin{array}{l}\text { QUANTIDADE } \\
\text { UTILIZADA }\end{array}$ & $\begin{array}{l}\text { GASTO } \\
\text { (R\$) }\end{array}$ \\
\hline DOCE DE LEITE & $4,6 \mathrm{KG}$ & $\mathrm{R} \$ 17,00$ & & \\
\hline FARINHA DE TRIGO & $25 \mathrm{KG}$ & $\mathrm{R} \$ 46,50$ & & \\
\hline LEITE & $\begin{array}{lll}\text { CX COM } & 12 \\
\text { LITROS } & \end{array}$ & $\mathrm{R} \$ 19,80$ & & \\
\hline GLUCOSE DE MILHO & $1 \mathrm{KG}$ & $\mathrm{R} \$ 7,50$ & & \\
\hline MARGARINA & $1 \mathrm{KG}$ & $\mathrm{R} \$ 6,30$ & & \\
\hline FERMENTO QUÍMICO & 100 GRMS & $\mathrm{R} \$ 2,02$ & & \\
\hline BICARBONATO DE SÓDIO & 80 GRMS & $\mathrm{R} \$ 2,62$ & & \\
\hline CANELA EM PÓ & 50 GRMS & $\mathrm{R} \$ 4,50$ & & \\
\hline EMBALAGEM & 25 UNIDADES & $\mathrm{R} \$ 18,25$ & & \\
\hline $\begin{array}{l}\text { CUSTO PARA PRODUZIR } \\
\text { UMA UNIDADE }\end{array}$ & & & & $\mathbf{R} \mathbf{S}$ \\
\hline
\end{tabular}

Quadro 1 - Exemplo de atividade desenvolvida

Assim, as atividades abordaram o conteúdo de cálculos proporcionais e porcentagem, e foram trabalhadas a partir de situações-problemas elaboradas considerando-se o contexto 
sociocultural do grupo e visando auxiliar às integrantes do $\mathrm{BC}$ a terem maior autonomia durante as análises e controle de créditos produtivos que o banco concede aos EES.

\subsection{Aspectos gerais referentes à aplicação das atividades}

A realização das oficinas de educação matemática teve como objetivo oferecer ao grupo aqui estudado uma orientação diferenciada em matemática, dando ênfase aos conteúdos matemáticos inerentes ao preenchimento da planilha utilizada no trabalho com o $\mathrm{BC}$, visando à compreensão e aquisição dos conhecimentos envolvidos e valorizando os saberes adquiridos nas interações com o cotidiano de trabalho dessas pessoas.

Em relação à aplicação das atividades, observamos, inicialmente, que $A$ e $B$ tiveram menos dificuldades durante a resolução dos exercícios propostos, pois se lembraram de alguns conteúdos vistos nos tempos da escola; embora, percebemos que ambas tinham dificuldades na leitura e interpretação das situações-problemas propostas, nos cálculos com números decimais e também em organizar seus raciocínios. No entanto, observamos que $C$ conseguia, somente com muita dificuldade, executar operações elementares de matemática, tais como: somar, multiplicar e dividir, utilizando números naturais não nulos. Algumas vezes, $C$ nos disse: "[...] eu tento ajudar meus filhos na tarefa da escola, mas matemática pra mim é um bicho de sete cabeças".

De modo geral, percebemos que todas as integrantes do BC tinham dificuldades para efetuar operações básicas de divisão, especialmente quando se tratava de números decimais ou de inteiros, cujos resultados das divisões não eram exatos. Por conta disso, mostrou-se necessário o trabalho com a ressignificação dos números decimais, pois se observou que elas apresentavam dificuldades em diferenciar, por exemplo, 4,5 de 4,05 ou de 4,005.

Durante as intervenções, trabalhamos, também, o uso da calculadora, visando auxiliálas na realização dos cálculos; fizemos uma comparação entre fazê-los com o uso da calculadora e manualmente. Dessa maneira, percebemos que elas tiveram mais facilidade em resolver os cálculos e passaram a fazer uso da calculadora de forma mais consciente fator importante, já que elas utilizam muito a calculadora no cotidiano de trabalho do $\mathrm{BC}$, a fim de agilizar as análises dos créditos solicitados pelos EES.

\subsection{Sobre os resultados das intervenções realizadas}


Após a realização das oficinas de educação matemática, observou-se que diversas dificuldades enfrentadas pelas integrantes do $\mathrm{BC}$, referentes a conteúdos matemáticos, foram sanadas, percebeu-se, por exemplo, melhora na organização do raciocínio matemático para resolver uma situação-problema sobre proporção utilizando o algoritmo de regra de três: "Tem que pegar a quantidade e o valor e colocar quantidade embaixo de quantidade e valor embaixo de valor..." (AGENTE DE CRÉDITO $C$ ).

Observou-se, também, uma melhora quanto à realização de algumas operações básicas envolvendo divisão e multiplicação de números decimais e quanto ao uso da calculadora de forma mais consciente (por exemplo, houve uma ressignificação dos números mostrados no visor da calculadora). Percebeu-se que ocorreu uma compreensão de cálculos proporcionais, pois, inicialmente, elas utilizavam o algoritmo da regra de três com muita dificuldade para os cálculos proporcionais (contidos na planilha de análise e controle de crédito produtivo) e não sabiam o significado de proporção. Para título de ilustração, apresentamos alguns trechos do diálogo ocorrido no momento de realização de uma das atividades propostas:

C: 19,80 vezes 1 é 19,80 reais mesmo!

Pesquisador-aplicador da atividade: Sim é verdade, mas o que temos que fazer depois que multiplicar por 1 ?

B: A gente tem que achar o x e tem que passar o 12 dividindo...

Pesquisador-aplicador da atividade: Sim, mas por que eu passo esse 12 dividindo?

B: Acontece que a gente quer um x só e a gente tem $12 x$ !

C: Nossa... assim é muito mais fácil e rápido... eu não quero mais saber de regra de três..." [referindo-se à realização de cálculos proporcionais, sem a utilização do algoritmo de regra de três para organizar as ideias e posteriormente realizar o cálculo com o uso da calculadora] (FALAS DAS INTEGRANTES DO BC).

Ao final das intervenções, procurou-se conhecer, através das concepções obtidas pelas falas das integrantes do BC, de que maneira as oficinas em Educação Matemática contribuíram para o conhecimento matemático dos seus cotidianos e se elas tinham interesse em continuar participando de oficinas dessa natureza. Através dessas falas foi possível perceber que elas demonstraram ter levado uma parcela do que foi trabalhado nas oficinas em suas tarefas diárias, pois afirmaram ter usado as operações em diversas situações:

B: sim [mudou alguma coisa em relação ao que eu já sabia] porque fazia na calculadora, mas agora aprendi fazer no papel [...] utilizei [a adição e subtração] no salário do meu marido para saber quanto a gente pode gastar no mês.

A: Sim [tem relação com o que eu faço] porque eu mexo com o produto de limpeza também lá no LIMPSOL ${ }^{6}[\ldots]$ eu utilizei em algumas contas como na venda dos produtos lá da cooperativa (FALAS DAS INTEGRANTES DO BC).

\footnotetext{
${ }^{6}$ O LIMPSOL é um Empreendimento Econômico Solidário, que fabrica produtos de limpeza, em que a $A$ também atua.
} 
Também, sobre as oficinas de Educação Matemática, notamos, através das falas dessas pessoas, que elas perceberam a necessidade de dar continuidade ao processo iniciado:

B: participaria [de outras oficinas de Matemática] porque quanto mais eu aprender melhor é para mim e para o futuro do Banco, ainda mais também que eu vou prestar alguns concursos, e matemática cai muito nesses concursos....

A: Eu gostaria que dessem continuidade nas oficinas, porque eu aprendi muito [...] mas aprendi pouco porcentagem.

$C:[\ldots]$ decidi que quero aprender mais a matemática e se estiver mais uma vez um mini curso eu gostaria de voltar a participar [...] eu hoje me sinto com vontade de aprender matemática, de entender mais coisas, pois acho que estou deixando de ver a matemática, como se diz o ditado, como um bicho de sete cabeça, acho que foi muito legal estas oficinas pra mim (FALAS DAS INTEGRANTES DO BC).

Em função do tempo de realização das intervenções, observou-se que nem todas as dificuldades do grupo foram sanadas, o que indicou a necessidade de dar continuidade às atuações nessa direção. Apesar disso, das intervenções realizadas, percebeu-se que houve compreensão de alguns conceitos importantes para o grupo; o trabalho realizado proporcionou às integrantes do grupo maior autonomia na realização das atividades inerentes ao trabalho junto ao BC e, também, em outras atividades de seus cotidianos. Além disso, foi possível observar que as intervenções pedagógicas despertaram o interesse dessas pessoas em relação à matemática.

\section{Considerações finais}

Nesta investigação, pautados principalmente nos pressupostos teóricos da Etnomatemática, num primeiro momento buscou-se conhecer o universo de inserção do grupo, os conhecimentos matemáticos inerentes às atividades do $\mathrm{BC} \mathrm{e}$ as principais dificuldades dessas pessoas quanto ao uso da matemática no contexto do BC. Desse levantamento inicial, observou-se que a matemática se fazia presente em toda cadeia produtiva do $\mathrm{BC}$, em especial na gestão financeira e logística desse EES. Além disso, foi possível perceber que as maiores dificuldades, no que se refere ao uso de conceitos matemáticos, estavam relacionadas ao manuseio da planilha de análise e controle de crédito produtivo. A partir disso, iniciamos a elaboração de um plano de atividades para tratar os conceitos matemáticos envolvidos nessa planilha por meio de situações-problemas do contexto do BC.

Assim, as intervenções pedagógicas realizadas inseriram-se numa proposta de trabalhar conteúdos matemáticos que compõem a planilha, embasados no contexto sociocultural no qual se encontram esses indivíduos e valorizando os conhecimentos prévios 
de cada componente do grupo. Dessa forma, pretendeu-se, também, auxiliar as integrantes do $\mathrm{BC}$ a terem maior autonomia durante as análises e controle de créditos produtivos. Durante as intervenções realizadas houve a interação entre educador e educando, por meio de uma relação dialógica, na qual todos os participantes tiveram liberdade de expressar suas ideias sobre as situações abordadas. Nesse sentido, percebeu-se que houve um ambiente profícuo de aprendizagem no qual foi possível estabelecer uma conexão entre a realidade dessas pessoas e um novo conteúdo a ser aprendido.

Os conteúdos de Matemática foram trabalhados de forma contextualizada à realidade sociocultural dos membros do $\mathrm{BC}$, focando o processo de construção de conceitos e organização pessoal dessa realidade. Além disso, o trabalho com a matemática se deu de modo não formal, porém contextualizado, a fim de que essas trabalhadoras pudessem perceber e compreender os conteúdos matemáticos necessários às atividades do $\mathrm{BC}$; fato que se deu a partir da ampliação de suas experiências e de seus conhecimentos prévios. Trabalhando dessa maneira, percebeu-se que o processo de ensino e aprendizagem respeitou a individualidade das integrantes do BC, já que cada uma delas possuía grau de escolaridade diferente, o que motivou, em certo momento, a observar a diferença no tempo gasto e a maneira com que cada uma interagia com o conteúdo abordado. Com isso, observou-se que embora a integrante que tinha grau de escolaridade mais elevado tenha aprendido os conteúdos com mais facilidade e mais rapidamente, a integrante com grau de escolaridade mais baixo também conseguiu acompanhar o desenvolvimento dos conceitos matemáticos envolvidos na planilha de análise e controle de crédito produtivo. Assim, observou-se que houve compreensão dos conceitos envolvidos por todas as integrantes do BC. Percebeu-se, portanto, que diversas dificuldades enfrentadas pelas integrantes desse banco (referentes aos conteúdos matemáticos do cotidiano do BC) foram sanadas, possibilitando, com isso, maior autonomia dessas pessoas na gestão do BC.

Ressalta-se, além disso, que o trabalho efetuado também auxiliou na autogestão desse EES, visto que esta "pressupõe uma participação ativa dos trabalhadores em todas as etapas do planejamento e de gestão do empreendimento" (GALVÃO; CIFUENTES, 2001, p. 38).

Entende-se que a partir de ações de educação matemática, tais como as focadas neste artigo, os membros do BC puderam adquirir, pela apropriação adequada de conhecimentos matemáticos, maior compreensão dos processos produtivos nos quais eles estão inseridos. Uma vez que essa compreensão ocorra, essas pessoas poderão atuar de modo mais eficaz na cadeia de produção e gestão desse EES. 
Portanto, como resultado foi possível perceber que as intervenções pedagógicas realizadas, nas quais se confrontou os conteúdos abordados com a realidade do $\mathrm{BC}$, focando o processo de construção dos conceitos matemáticos envolvidos, auxiliou o grupo quanto à organização e à compreensão das atividades do BC e com isso contribuiu, também, com a autogestão deste EES.

\section{Agradecimentos}

As autoras agradecem às integrantes do Banco Comunitário pela participação no projeto e aos membros do NUMIES pela parceria; à Pró Reitoria de Pesquisa - RUSP ${ }^{7}$, aos Proext 2014/MEC; Proext 2015/MEC (cujas metas estão relacionadas ao desenvolvimento desta pesquisa e atuação).

\section{Referências}

BRASIL. Ministério do Trabalho e Emprego. Secretaria Nacional de Economia Solidária. Atlas de Economia Solidária no Brasil 2005. Brasília: MTE, SENAES, 2006a. 60p.

BRASIL. Ministério do Trabalho e Emprego. Secretaria Nacional de Economia Solidária (Senaes). I Oficina Nacional de Formação/Educação em Economia Solidária: documento final. Brasília: MET, SENAES, SPPE, DEQ, 2006b. 47p.

BRASIL. Ministério da Educação. Secretaria da Educação Fundamental. Proposta curricular para a educação de jovens e adultos: segundo segmento do ensino fundamental. v.3, Brasília, 2002. 240 p.

CORÔA, R. P. Saberes construídos pelos professores de matemática em sua prática docente na educação de jovens e adultos. 2006, 110 f. Dissertação (Mestrado em Educação em Ciências e Matemática) - Universidade Federal do Pará, Belém, 2006.

D’AMBROSIO, Ubiratan. Educação Matemática: da teoria à prática. Campinas: Papirus, 1996.

D’AMBROSIO, U. Etnomatemática: elo entre as tradições e a modernidade. Minas Gerais: Autêntica, 2001. 112p.

D’AMBrosio, U. Sociedade, cultura, matemática e seu ensino. Educação e Pesquisa, São Paulo, v. 31, n.1, p. 99-120, jan./abr., 2005.

FREIRE, P. Pedagogia da autonomia: saberes necessários à prática educativa. 43. ed., São Paulo: Paz e Terra, 2011.92p.

GALVÃO, M. N.; CIFUENTES, R. Cooperação, autogestão e educação nas novas configurações de trabalho. Revista Org \& Demo, Marília v. 2, p. 29-40, 2001.

GASPAR, A. A educação formal e a educação informal em ciências. In: MASSARANI, L.; MOREIRA, I. C.; BRITO, F. Ciência e público: caminhos da divulgação científica no Brasil. Rio de

\footnotetext{
${ }^{7}$ A segunda autora atuou junto ao BC por meio de projeto de iniciação científica sob orientação da primeira como apoio da Pró-Reitoria de Pesquisa/ RUSP.
} 
Janeiro: Casa da Ciência - Centro Cultural de Ciência e Tecnologia da Universidade Federal do Rio de Janeiro. Fórum de Ciência e Cultura, 2002. p. 171-183.

GOHN, M.G. Educação não-formal, participação da sociedade civil e estruturas colegiadas nas escolas. Revista Ensaio: Avaliação e Políticas Públicas em Educação, Rio de Janeiro, v.14, n. 50, p. 27-38, jan./mar., 2006.

KNIJNIK, G. Pesquisa em Etnomatemática: apontamentos sobre o tema. In: FANTINATO, M. C. C. B. (Org.). Etnomatemática: Novos desafios teóricos e pedagógicos. Niterói (Brasil), Editora da Universidade Federal Fluminense, 2009, p.135-142.

LÜDKE, M.; ANDRÉ, M. E. D. A. Pesquisa em Educação: abordagens qualitativas. São Paulo: EPU, 1986.

MENEGHETTI, R. C. G. Educação matemática e economia solidária: uma aproximação por meio da etnomatemática. Revista Latinoamericana de Etnomatemática, San Juan de Pasto, v. 6, n. 1, p. 4066, julho, 2013.

MOREIRA, D. Etnomatemática e mediação de saberes matemáticos na sociedade global e multicultural. In: FANTINATO, M. C. C. B. (Org.). Etnomatemática: novos desafios teóricos e pedagógicos. Niterói: Editora da Universidade Federal Fluminense, 2009, p. 57-66

MAFRA, J. R. S. A etnomatemática como instrumento na resolução de problemas: saberes em constante conjunção. In: ENCONTRO DE PESQUISA EM EDUCAÇÃOO DA UFPI, 2. 2002, Teresina. Anais... Teresina: UFPI, 2002. Disponível em:

$<$ http://www.ufpi.br/subsiteFiles/ppged/arquivos/files/eventos/evento2002/GT.1/GT1 20 2002.pdf >

Acesso em: 15 nov. 2014.

PAULA, E. M. A. T. Educação popular, educação não formal e pedagogia social: análise de conceitos e implicações para educação brasileira e formação de professores. In IX CONGRESSO NACIONAL DE EDUCAÇÃO - EDUCARE. III ENCONTRO SUL BRASILEIRO DE PSICOPEDAGOGIA, Curitiba, 2009. Anais... Curitiba: PUCPR, 2009. Disponível em <http://www.pucpr.br/eventos/educere/educere2009/anais/pdf/2103_1034.pdf > Acesso em: 26 out.2015.

PEREIRA, S. K. A utilização de software na Educação de Jovens e Adultos: uma alternativa para o ensino de língua inglesa no NAES- Gaspar. 2006, 145f. Dissertação (Mestrado em Educação) Fundação Universidade Regional de Blumenau, Blumenau, 2006.

ROSA, M.; OREY, D. C. Abordagens atuais do Programa Etnomatemática: delineando um caminho para a ação pedagógica. Bolema, Rio Claro, v. 19, n. 26, p.19-48, 2006.

SINGER, P. Globalização e Desemprego: diagnóstico e alternativas. São Paulo: Editora Contexto, 1998.

SINGER, P. Introdução à Economia Solidária. São Paulo: Fundação Perseu Abramo, 2002.

TAFURI, D. M. A experiência educativa da gestão de um banco comunitário na periferia de São Carlos/ SP. 2014, 183 f. Dissertação (Mestrado em Educação) - Centro de Educação e Ciências Humanas, Universidade Federal de São Carlos, São Carlos, 2014.

THIOLLENT, M. Metodologia da pesquisa-ação. São Paulo: Cortez Editora, 2011. 36p. 
VIERO, A. As práticas educativas na educação de jovens e adultos da rede pública de Porto Alegre-RS. 2008, 484 f. Tese (Doutorado em Educação) - Faculdade de Educação, Universidade Federal do Rio Grande do Sul, Porto Alegre, 2008.

Submetido em Abril de 2015. Aprovado em Setembro de 2015. 